1Secretaria Estadual de Saúde de Pernambuco (SES-PE)

-Recife (PE), Brasil. vanessaalves10@hotmail. com

2 Universidade de Pernambuco (UPE) - Recife (PE), Brasil.

\section{As psicologias construídas no SUS: possibilidades e desafios profissionais no agreste pernambucano}

\author{
The psychologies built in the SUS: professional possibilities and \\ challenges in the Agreste Pernambucano
}

Vanessa Alves de Souza', Érika de Sousa Mendonça²

DOI: $10.1590 / 0103-1104202012716$

RESUMO O artigo aborda a atuação do psicólogo no Sistema Único de Saúde (SUS), sob a perspectiva de profissionais inseridos nos contextos da Atenção Primária à Saúde e da média complexidade. O objetivo foi investigar práticas psicológicas realizadas, discutindo possibilidades e desafios. A pesquisa utilizou-se do método qualitativo, buscando a construção de informações e reflexões a partir das narrativas de dez psicólogos atuantes em quatro municípios do agreste pernambucano. Após aprovação do projeto de investigação junto ao Comitê de Ética em Pesquisa, foram realizadas entrevistas individuais, semiestruturadas, que foram posteriormente transcritas e categorizados segundo as técnicas da Análise de Conteúdo. Constatou-se que a atuação do psicólogo no SUS tem sido refletida pelos profissionais, que apontam necessidade de revisão de propostas nos cursos universitários, uma vez que chegam despreparados para a atuação frente ao SUS. O resultado evidencia a ampliação de possibilidades de atuação, com experimentações e articulações multidisciplinares, ao mesmo tempo que se revela que esses psicólogos não dialogam entre si, numa construção coletiva de seus fazeres cotidianos. Por fim, defende-se que uma atuação profissional técnica, instrumentalizada e reconhecida é tão necessária quanto um fazer que se põe em abertura aos devires de um fazer da psicologia junto ao SUS.

PALAVRAS-CHAVE Psicologia. Local de prática profissional. Sistema Único de Saúde.

\begin{abstract}
The article addresses the role of the psychologist in the Unified Health System (SUS), from the perspective of professionals inserted in the contexts of primary health care and medium complexity. The objective was to investigate psychological practices carried out, discussing possibilities and challenges. The research used the qualitative method, seeking the construction of information and reflections based on the narratives of ten psychologists working in four municipalities in the Agreste Pernambucano. After approval of the research project by the Research Ethics Committee, individual and semi-structured interviews were conducted, which were later transcribed and categorized according to the Content Analysis techniques. It was found that the psychologist's performance in the SUS has been reflected by the professionals, who point out the need to review proposals in university courses, since they arrive unprepared to perform on the SUS. The result shows the expansion of possibilities of action, with multidisciplinary experiments and articulations, at the same time that it is revealed that these psychologists do not dialogue with each other, in a collective construction of their daily activities. Finally, it is argued that a technical, instrumentalized, and recognized professional performance is as necessary as a task that opens itself up to the becoming of a Psychology practice with SUS.
\end{abstract}

KEYWORDS Psychology. Professional practice location. Unified Health System. 


\section{Introdução}

O Sistema Único de Saúde (SUS) é uma das reverberações da efervescência do movimento sanitário brasileiro, que se deu de modo mais incisivo na década de 1980. A partir dessa eclosão de discussões e propostas, foi criado, em 1988, o SUS, regulamentado pela Constituição Federal do corrente ano, tendo como princípios a universalidade, a equidade e a integralidade. A saúde passou a ser um direito e não um privilégio ou caridade, tornando-se universal para todos e devendo ser provida pelo Estado'.

Em 19 de setembro de 1990, foi formulada a Lei ${ }^{\circ} 8.080$, conhecida como a Lei do SUS, que prevê as condições para a promoção, proteção e recuperação da saúde, a organização e o funcionamento dos serviços correspondentes, tendo por objetivo regulamentar as ações e os serviços em saúde em todo o território nacional2 ${ }^{2}$.

O SUS trouxe consigo um movimento que conduziu profissionais de saúde a desenvolverem ações em saúde, considerando que o meio em que a pessoa está inserida, as formas de viver e conviver, as relações interpessoais e sociais estabelecidas, o modo como homem e o meio interagem interferem diretamente no modo ampliado de conceber a saúde, pois esta perpassa questões existenciais que vão além de somente tratamentos e prevenções aplicados de modo generalizável a qualquer pessoa. As intervenções em saúde requerem um olhar mais singular para o sujeito que se constitui como usuário do serviço. Nessa concepção, a saúde passa a ser compreendida como um estado dinâmico e socialmente produzido ${ }^{3}$.

Isto posto, volta-se o olhar para a psicologia, que, no ano de 1962, é regulamentada como formação e profissão através da Lei Federal $n^{0}$ 4.119 , coincidindo com o período imediatamente anterior à ditadura militar e sofrendo, portanto, a influência histórica de um movimento de controle das massas pela classe dominante. Naquele contexto circunscrito, foi criada uma psicologia voltada, prioritariamente, aos interesses das classes dominantes ${ }^{4}$.
Tornam-se compreensíveis, desse modo, os desafios assumidos por psicólogos que precisam lidar com a expansão da psicologia para focos diversificados, o que inclui, sobretudo a partir da década de 1980, a inserção da psicologia no SUS. O profissional de psicologia passa a atuar, adentrar e se inserir em instituições de saúde e em comunidades, tendo como foco essa nova concepção de saúde e, portanto, ampliando perspectivas no olhar e no cuidado ao usuário.

Trata-se de um cenário em que se impõe a necessidade de revisão e ampliação de modos de intervir, levando-se em conta tanto a necessidade de adaptação a questões espaciais (não há, por exemplo, um setting terapêutico bem definido) como de características e demandas específicas da população e da localidade atendida. A transferência da atuação clínica individual e particular para os espaços públicos, por sua vez, não traz consigo as respostas necessárias às demandas comunitárias e contextualizadas ${ }^{5}$.

Assim é que tal ampliação no caminhar profissional do psicólogo provocou, também, a necessidade de uma revisão de bases teóricas e práticas que fundamentam sua atividade no SUS, recorrendo a saberes não apenas da psicologia clínica, mas compreendendo igualmente a psicologia comunitária, a psicologia social e a psicologia política, e, mais que isso, reconhecendo o papel político do psicólogo na transformação de realidades violentas, naturalizadas, as quais repercutem diretamente na condição de saúde da população. É assim que o psicólogo é convocado a atuar para além do nível intrapsíquico, na sintonia com o contexto social, cultural, político e estrutural em que o sujeito está inserido.

Também, estudos de políticas públicas e uma compreensão ampliada da própria noção de saúde se fizeram necessários. Apenas compreendendo os determinantes sociais de saúde que, segundo o Ministério da Saúde, tratam das características sociais dentro das quais a vida transcorre, levando em consideração as condições de vida e de trabalho dos sujeitos, sendo possível compreender seus impactos na saúde mental da população ${ }^{6}$. 
A entrada dos psicólogos na saúde pública sugere, enfim, a abertura de novos campos de atuação, o que, por sua vez, passa a requerer, também, transformações na prática realizada. Tal fato traz, em si, a necessidade de novas perspectivas teóricas e criatividade na construção de práticas de atenção psicológica. E, nesse sentido, afirma-se que há um defrontamento com a emergência de um novo campo de saber?

Diante de tal cenário, indaga-se: como vem se dando a atuação de psicólogos no SUS? Para esta discussão, considera-se relevante um balizamento nas reflexões de profissionais de psicologia que vêm desbravando possibilidades e desafios no exercício profissional no referido sistema, na atenção primária e na média complexidade em saúde. É nessa direção, pois, que se propõe uma reflexão tangenciada pela teoria e ampliada pelas vivências de profissionais que atuam cotidianamente no SUS.

Assume-se, desse modo, o lugar da psicologia como ciência que tem por mérito a produção de conhecimento do social, no social e para o social, estando as partes envolvidas na pesquisa - pesquisador e pesquisado - atuando como agentes transformadores de realidades e multiplicadores de saberes ${ }^{8}$.

\section{Material e métodos}

Para o estudo, foi eleito o método de pesquisa qualitativa, que confere a possibilidade de compreender, por meio das narrativas dos sujeitos, o contexto em que a pesquisa acontece e as vivências dos interlocutores no âmbito da saúde pública, através das histórias compartilhadas, dos significados e dos sentidos atribuídos, dos motivos, das crenças, dos valores, da cultura e das atitudes dos participantes da pesquisa ${ }^{9}$.

O referido estudo foi realizado junto a dez profissionais de psicologia que atuam em unidades públicas de saúde em cidades do agreste pernambucano - totalizando quatro municípios -, tanto no contexto da Atenção Primária à Saúde (APS) (nesse caso, foi selecionado o Núcleo de Apoio à Saúde da Família - Nasf) quanto na média complexidade (nesse caso, o hospital).

Como recurso para construção de dados, foram realizadas entrevistas semiestruturadas, as quais permitem evocar uma fala livre, que atenda aos objetivos da pesquisa e que seja simbólica e significativa no contexto de sua realização ${ }^{10}$. As entrevistas foram realizadas nas respectivas cidades em que os profissionais trabalham, sendo gravadas com autorização dos participantes, em atenção aos cuidados éticos de pesquisar.

Após a realização das entrevistas e sua transcrição integral, com fins de acessar todos os conteúdos enunciados pelos psicólogos, passou-se ao procedimento técnico de interpretação dos dados: a análise do conteúdo"1. Essa é composta por três etapas, a saber: a pré- análise, a exploração do material e o tratamento dos resultados, com a inferência e a interpretação.

Na etapa da pré-análise, concretiza-se a organização da pesquisa. Nesse momento, sintetizam-se as ideias iniciais, planejando de modo flexível, porém preciso, a forma de conduzir a análise de conteúdo. Realizase, em seguida, a leitura flutuante, que aos poucos vai se tornado cada vez mais precisa, desembocando nas possibilidades de projeções teóricas e possível aplicabilidade de materiais equivalentes ao conteúdo que será analisado"1.

Na segunda etapa, caracterizada pela exploração do material, coloca-se em prática o que foi planejado e sintetizado. Nesse momento, são realizadas as operações de codificações e decomposição, em função de objetivos previamente formulados ${ }^{11}$.

Na terceira e última etapa, estrutura-se a proposta metodológica. Nesse momento, são tratados e interpretados os dados obtidos. Alia-se o que foi executado nas duas primeiras etapas à interpretação dos resultados brutos, de forma que estes se tornam válidos e significativos, havendo a proposição de inferências, visando a realizar nossa interpretação com base nos objetivos pretendidos, dando espaço para que outros conteúdos 
pudessem emergir. Com isso, há a possibilidade de lançar compreensões e reflexões acerca da temática pesquisada.

As instituições de saúde a que se vinculam e seus nomes foram preservados com base na Resolução $n^{\circ} 466$, de 12 de dezembro de 2012. Para tanto, optou-se por identificar os participantes da seguinte maneira: Psicólogo/a 01, Psicólogo/a 02 (e assim sucessivamente), de acordo com a expressão de sua fala no decorrer da discussão dos resultados.

Destaca-se que a investigação obedeceu a todos os critérios éticos, tendo seu projeto aprovado pelo Comitê de Ética em Pesquisa, CAAE: 17971313.1.0000.5207 - Parecer: 382.130. Para a realização das entrevistas, foi utilizado o Termo de Consentimento Livre e Esclarecido (TCLE), tendo, antes, sido assinado o Termo de Confidencialidade, bem como foram obtidas as Cartas de Anuência das instituições onde os psicólogos atuam. Para além dos critérios prescritivos, esteve-se todo tempo com atenção a quaisquer sinais de desconforto dos interlocutores, que, afinal, não foram percebidos.

\section{Resultados e discussões}

De posse dos dados colhidos, foram construídas categorias temáticas considerando-se as falas que mais se destacaram nos encontros com os participantes, seja pela aproximação, seja pela dissonância das argumentações construídas pelos informantes. Foram eleitas, dessa forma, as seguintes categorias temáticas: 1 ) formação do profissional de psicologia; 2) percepção do psicólogo acerca de sua atuação e da inserção da psicologia no SUS; e 3) desafios e perspectivas consoantes com a atuação do psicólogo no SUS.

Na primeira categoria temática - formação do profissional de psicologia -, foram tratadas as percepções dos psicólogos acerca de sua formação acadêmica (graduação ou pós-graduação) e de como ela traz contribuições ou, por outro lado, revela escassez de informações, promovendo o preparo ou o despreparo teórico e prático para a atuação profissional junto ao SUS.

Compreende-se, nesta pesquisa, que a formação em psicologia ainda está galgada em um modelo e/ou conceito clássico de clínica que é privada, curativa e individual, inspirada na prática médico-curativista ${ }^{\mathbf{1 2}}$.

Durante a graduação dos participantes da pesquisa, por exemplo, $90 \%$ dos entrevistados realizaram o estágio curricular obrigatório na clínica da Instituição de Ensino Superior (IES) onde realizaram sua formação acadêmica. Nesse sentido, vê-se que a formação do psicólogo ainda é predominantemente marcada pela proposta clínica tradicional, que deixa negligenciadas possíveis ferramentas teóricas, técnicas e críticas para atuação no SUS ${ }^{13}$.

A esse respeito, psicólogo/a 01 afirma:

A formação da própria faculdade levava a gente a fazer essa decisão de ir pela clínica, pelo consultório... Não levava a gente a pensar em outras áreas afins, como: hospitalar, escolar. A gente ficava fissurado mesmo em buscar a clínica, atender o paciente ou então fazer formação de grupo. A faculdade oferecia outras possibilidades de estágio, mas a gente naquele momento só via a área maior [se referindo à clínica], a gente não se interessava pelo resto.

Percebe-se, nesse relato, não só a atuação clínica individual sendo tradicionalmente difundida pela IES, mas também um tipo de retroalimentação social para essa vertente de fazer e produzir conhecimento psicológico, em que a clínica tradicional e individual se apresenta como uma forma difundida e esperada de se exercer a psicologia.

A formação para a clínica foi bastante difundida até a década de 1990, produzindo reverberações nos dias atuais, sendo uma delas o entendimento de que o psicólogo é um profissional que atua em consultório privativo, somente $\mathbf{1 4}^{\mathbf{4}}$.

Outra perspectiva mostra o vislumbre de distintos espaços de atuação profissional por 
parte dos psicólogos em seu momento de formação, como atesta psicólogo/a 02: "Realizei estágios em escola, realizei em hospital psiquiátrico, em clínica do Detran e realizei na clínica da faculdade”. Já psicólogo/a 01 relata: "Eu fui para área clínica mesmo".

Essas falas indicam que, mesmo havendo outros interesses e possibilidades de atuação, a prática clínica de consultório, individualizada, é bastante procurada pelos graduandos em psicologia, configurando-se como uma parte essencial à formação do psicólogo. Veja-se um trecho da narrativa de psicólogo/a 03: "Tinha mais interesse na parte clínica. Eu sempre tive muito interesse na clínica". Tal fala é reafirmada por psicólogo/a 04: "E meu interesse naquela época sempre foi na área clínica”.

No campo da saúde pública, o psicólogo ainda esbarra com alguns limites teóricos e técnicos de sua formação universitária, que, muitas vezes, não oferece embasamento suficiente para que o profissional possa responder à demanda da população que é atendida pelas unidades de saúde de forma efetiva ${ }^{15}$.

No entanto, percebe-se que há uma sutil modificação nas formas de pensar a formação do psicólogo que tem reverberado na estrutura dos cursos de graduação e na crítica que é feita pelos próprios profissionais à sua formação. Como narra psicólogo/a 05:

Ninguém mais pode sair da faculdade e reclamar que só foi clínico. E aí fica mais fácil quando você conhece, né? De entrar na psicologia nessa área, no social.

Aqui, percebe-se uma ampliação do campo de atuação do psicólogo através da preocupação sobre o contexto social na prática clínica, lançando bases para o fortalecimento da clínica ampliada ${ }^{16}$. Sob essa perspectiva, percebe-se que Clínica Ampliada enseja que o profissional de saúde expanda o cuidado à pessoa, enfocando a saúde e não a doença, contribuindo para maximizar sua vida ${ }^{\mathbf{7}}$.

Como diz psicólogo/a 04: "É importante conhecer o aspecto social, político, econômico, as crenças, e isso devagarinho é que vai acontecendo, mas muito lentamente ainda". Aqui, veem-se rudimentos de uma mudança paradigmática na qual, por exemplo, a psicoterapia, com sessões que se prolongam por longo tempo, tende a ceder espaço para a importância de entender o contexto em que a população a ser assistida está inserida, quais as significações atribuídas às suas vivências cotidianas e o modo como ela é afetada por essas.

Essa perspectiva de ampliar os fundamentos da psicologia foi destacada por todos os entrevistados, que defendiam a necessidade de expandir seus conhecimentos teóricos, recorrendo a programas de pós-graduação para melhor embasamento de sua prática profissional. Algumas falas ilustram esse debate. Psicólogo/a 05 afirma: "Procurei me aprimorar mais na área da saúde”. Outras narrativas também vão nessa direção:

Eu sempre tive interesse pela saúde pública, mas quando eu tive contato, mesmo trabalhando no Nasf, eu vi a necessidade de ampliar o conhecimento a respeito do SUS, e pude conhecer mais e pude intervir de formas diferentes. Depois que eu comecei a trabalhar é que eu comecei a especialização. Eu acho que na própria graduação é preciso trabalhar melhor isso [referindo-se à atuação do psicólogo no SUS]. Eu acho que a gente não vê muito a realidade em si. Eu acho que é trabalhado teoria, mas quando a gente entra em contato com a população, principalmente pobre, a gente vê as dificuldades, então a gente se sente despreparado, por isso a necessidade de se especializar para poder atuar. (Psicólogo/a 06).

Nas narrativas dos entrevistados, percebem-se tanto mudanças e ampliações ocorridas em sua formação quanto fica evidenciado que ainda há um longo caminho a percorrer para que se construa uma forma de atuar adequada à inserção e à prática profissional no SUS. Vale ressaltar, também, que as IES possuem grades curriculares diversas, e isso reverbera uma formação diversificada para o profissional de psicologia. 
Vislumbram-se algumas mudanças na formação do psicólogo, entretanto, ainda se percebe uma tendência de amalgamar teoricamente o conhecimento da psicologia clínica à atuação do SUS. Tal atitude, porém, revela-se insuficiente e até incapaz de responder adequadamente às intervenções necessárias, segundo os próprios interlocutores do estudo. À medida que contextos e necessidades sociais se modificam, também a ciência - neste caso, a psicologia - precisa repensar seu modo de atuar diante dela ${ }^{18}$.

Isto posto, refletir-se-á a segunda categoria temática, discutindo sobre percepções do psicólogo acerca de sua atuação e da inserção da psicologia no SUS. Psicólogo/a 01 afirma: " $E u$ acho que a psicologia está desbravando uma visão bastante ampla do sujeito, que não é só psicológico e nem psíquico ou emocional, é integral".

Trata-se, nesse sentido, de perceber a pessoa para além da patologia ou do sofrimento psíquico, mas como ser de possibilidades que vive uma trama de relações sociais e interpessoais que geram ressonâncias no modo dos profissionais de saúde pensarem o processo saúde-doença. A pessoa é mais que um corpo físico, logo, a necessidade de uma visão integral da saúde é indiscutível ${ }^{19}$.

No que concerne à atuação do psicólogo, seja na APS, seja na média complexidade, os profissionais expressam a necessidade de buscar novas formas de intervir cotidianamente, como atesta psicólogo/a 06:

Vejo também que eu preciso melhorar mais, ampliar com os outros profissionais, reuniões e tudo para que a gente possa partilhar conhecimento. Mas, também, por outro lado, vejo que eu já avancei bastante, porque, no início, quando eu cheguei, não era feito nada de promoção, e hoje eu já consegui grupo de gestante, grupos de idosos e estou tentando outros. Os grupos são realizados nas Unidades Básicas. Eu sempre peço a contribuição de um profissional da Unidade, a enfermeira. Quando ela não pode, um técnico, qualquer pessoa. E, quando não tem, eu chamo alguém do próprio Nasf para me ajudar.
No instante em que se debruça para discutir a atividade do psicólogo no âmbito da saúde, está-se a pensar em sua atuação em uma organização. Ao refletir o contexto hospitalar, evidencia-se que ele se consolida como o epicentro do espaço da doença. Sob tal perspectiva, a atuação do psicólogo nesse espaço é regida por um ponto fulcral, que é minimizar o sofrimento decorrente do processo de hospitalização ${ }^{19}$.

Sobre esse aspecto, psicólogo/a 03 atesta:

No momento, ela [a atuação] é mais um apoio, certo!? Psicológico, breve, focal, ali tanto para o paciente, que está hospitalizado para minimizar justamente esses danos da hospitalização, quanto para familiares.

A psicologia hospitalar busca comprometer-se com questões ligadas à qualidade de vida dos usuários, seus familiares e dos profissionais da saúde, não devendo restringir-se apenas ao atendimento clínico, mesmo este sendo uma prática bastante disseminada entre os psicólogos hospitalares ${ }^{20}$.

Já na APS, o psicólogo atua na prevenção da doença e promoção da saúde, por meio do estabelecimento de vínculos de corresponsabilidade com a população, estimulando a autonomia, a participação social na implementação das ações e os serviços de saúde ${ }^{21}$. A narrativa de psicólogo/a 05 ilustra essa questão:

A gente faz grupo, grupo com gestante, com idosos, faz muita atividade de educação e saúde. E eu acho que é fundamental a gente não perder aquela força que vem da graduação, sabe? De querer fazer e querer construir e gostar do que faz. O principal de tudo, tem que gostar. Porque senão, não fica.

Percebe-se, também, que o conhecimento acerca do fazer do psicólogo no SUS ainda é associado à psicoterapia, como narra psicólogo/a 07:

Cobram muito da gente o psicoterapeuta, acham que todo mundo tem que fazer terapia, e a gente como sendo do Nasf é um leque na área de 
psicologia. Eu acho que... a gente trabalha com uma visão de clínica ampliada e tem uma série de coisas que às vezes chega queixa de todo canto, de escola, de tudo, aí tem que saber deslanchar as coisas.

Entretanto, como psicólogo/a $07 \mathrm{diz}$, " $a$ percepção de clínica ampliada requer um olhar multifacetado e tira o psicólogo do lugar de apenas um psicoterapeuta". A esse respeito, psicólogo/a 08 afirma: "Atuar em clínica é mais fácil, parece que é mais a nossa casa”. Deslocar-se da relação protegida que a clínica particular apresenta requer do psicólogo o enfrentamento da complexidade que é o processo de construir a realidade ${ }^{22}$.

Adotar essa postura traz à tona uma visão socialmente construída e reproduzida que atesta e coloca o psicólogo como psicoterapeuta em todos os espaços de atuação. Estando o psicólogo influenciado e atuando nessa mesma realidade, não se constitui uma tarefa simples deslocar-se da clínica tradicional, como psicoterapeuta, para a clínica ampliada.

O trabalho em equipe configura-se, sobretudo, como um sentimento de pertencimento e interesse em atingir um objetivo comum. No caso de equipes multiprofissionais, tem-se a presença de profissionais de saúde que trazem consigo saberes distintos, mas com foco no cuidado do sujeito que se apresenta ${ }^{23}$.

Destarte, o fato é que, além desse deslocamento, tem-se a interação dos múltiplos saberes que atuam de modo multidisciplinar no SUS. Com esse mote, segue-se para a próxima categoria temática, que tratará sobre a atuação do psicólogo em equipes multiprofissionais ${ }^{24}$.

Na APS na média complexidade, o psicólogo irá se defrontar com uma diversidade de saberes que compõe as equipes multiprofissionais. Psicólogo/a 09 diz:

Maravilhoso! Só vem fortalecer mais ainda os saberes [...] Eu acho magnífico! Que a gente termina entendendo também a prática de todos os profissionais e a gente vai ajudando um ao outro, encaminhando as principais demandas que surgem.
As equipes multidisciplinares se defrontam com o saber de cada disciplina de maneira a poder articular-se com as outras, com base no respeito mútuo para a realização de intervenções com vistas à compreensão da integralidade do sujeito ${ }^{24}$.

Percebe-se o supracitado na fala de psicólogo/a 02:

Eu acho que, como especialista na área do comportamento, especialista nas relações humanas, o psicólogo tende a facilitar esse convívio, então para mim, particularmente, eu acho muito fácil. Ao menos nos espaços onde eu estou trabalhando, eu me sinto muito acolhida e fazendo acolhimento das necessidades dos outros.

Atuar de modo multidisciplinar constitui-se como uma atividade complexa, pois é necessário estabelecer relações de interdependência entre a psicologia e outros saberes/fazeres da área da saúde, o que se revela um desafio à psicologia, que até então estava galgada em uma atuação solitária ${ }^{25}$.

Sobre essa temática, psicólogo/a 07 reflete:

É bom, por um lado, porque a gente vê também a prática do outro e enriquece a gente. Por um lado, é muito bom. Por outro lado, às vezes a gente quer fazer a coisa e tem as diferenças, né? Cada um tem suas diferenças, né? Mas acho que é um crescimento de modo geral. A gente junta o da gente com o do outro e a gente precisa. Na prática, eu vejo que a gente não pode estar isolado, né? Quem trabalha no Nasf depende da prática do outro.

Tratando da atuação multidisciplinar do psicólogo no âmbito hospitalar, tem-se uma equipe multidisciplinar que está centrada nas necessidades do sujeito em seu processo de hospitalização, logo, a demanda emerge a partir da necessidade desse sujeito. Nesse instante, é preciso que haja uma integração dos profissionais da saúde, com a finalidade de responder às necessidades postas.

Logo, indaga-se: como profissionais que atuam em unidades hospitalares concebem a 
sua atuação em equipes multidisciplinares? Psicólogo/a 01 responde:

Tem que aprender a lidar com essas coisas, com essa realidade, com as relações de grupo. Que não é muito fácil se relacionar com a equipe multiprofissional, com os casos e os descasos nesse caminho que acontece.

É imprescindível que o psicólogo conheça as atividades desenvolvidas pelos demais profissionais que compõem a equipe multidisciplinar, bem como os limites de cada um, possibilitando uma atuação integrada, com manejo único ${ }^{26}$.

Psicólogo/a 06 aponta:

A gente tem que se inquietar com a prática. $E$ procurar tanto buscar conhecimento, não só da psicologia como também de outras áreas. A gente precisa conhecer outras coisas e, também, procurar conversar com outros profissionais, abrir a mente para outras possibilidades e para atuar em conjunto.

Para tanto, muitas são as barreiras a transpor, uma vez que se está diante do encontro das subjetividades, das individualidades e da defrontação com as diversidades de saberes. Acredita-se que o caminho até aqui traçado permite visualizar a construção de uma psicologia voltada para o contexto do SUS. E muitos são os desafios para essa construção, que serão tratados neste instante, adentrando a última categoria temática: desafios e perspectivas consoantes com a atuação do psicólogo no SUS.

O desafio relativo à atuação no SUS é elencado por todos os participantes da pesquisa: trata-se de um desconhecimento inicial acerca do fazer, tanto por eles mesmos quanto pelos demais profissionais que compõem o SUS. Como afirma psicólogo/a 09:

Desafios, assim, foi o próprio desconhecimento da equipe do posto de saúde de aceitar a gente como profissional que vem contribuir, mais ainda, com os saberes um do outro.
A esse respeito, psicólogo/a 10 declara:

Primeiro desafio é o conhecimento do trabalho do psicólogo, né? [...] Então, o primeiro desafio da gente foi caracterizar o trabalho do psicólogo... A gente ter o trabalho do psicólogo reconhecido para as demandas virem.

Psicólogo/a 03 relata: "os desafios foram muitos. Ainda são, na verdade! Mas, no início, realmente não se tinha noção do que o psicólogo fazia dentro do hospital". As falas elencadas reluzem as percepções de psicólogos que atuam na APS e na média complexidade, e atenta-se para o fato de que, em ambos os casos, os desafios permeiam a não compreensão do fazer do psicólogo nesses âmbitos.

E como transpor esse desafio? Psicólogo/a 09 provoca:

A gente fez um trabalho de formiguinhas, que eles não davam muita atenção nas falas da gente, a própria equipe também, e os usuários principalmente, né? Então, foi preciso fazer reunião, falando da equipe, para mostrar a importância do serviço da equipe nos Nasf de uma forma geral, né? Da psicologia, que era um serviço que veio só a contribuir, que visa à prevenção e à orientação.

Reafirmando a fala de psicólogo/a 09, psicólogo/a 10 reitera: "a gente foi mostrando... $E$ a partir dai as pessoas foram reconhecendo o trabalho do psicólogo". Nessa linha, também psicólogo/a 03 argumenta:

Busquei lidar com a cara e a coragem! Entrando mesmo, sabe!? Respeitando muito o espaço, os profissionais, respeitando... Conversando sem que eles [os outros profissionais] se sintam intimidados com a nossa presença, mas que a gente pudesse também ir conquistando o espaço da gente.

A psicologia se insere no SUS buscando definir seu campo de atuação, contribuindo para a construção de ações que incorporem o biológico, o social e o psicológico, procurando 
abordar um indivíduo histórico e tangenciado pelo contexto social no qual está inserido ${ }^{27}$.

Psicólogo/a 01 assim declara:

eu acho que a gente enfrenta até hoje. Os desafios eles são permanentes. Eu acho que os desafios surgem até para que a gente possa encontrar novas formas de viver e atuar, de se relacionar.

Assim, entrelaçar a atuação profissional aos princípios do SUS pode trazer subsídios para ações desenvolvidas pelos psicólogos no referido sistema. A esse respeito, psicólogo/a 04 relata que:

Orientam, pois o SUS é uma rede, ou deveria ter essa perspectiva. Agora, se de um lado orienta porque trabalha em rede, é preciso também você enxergar o ser como rede.

Psicólogo/a 10 reflete a contribuição dos princípios do SUS para sua atuação profissional:

Eu acho que a missão do psicólogo é essa! Independente de SUS... Independente do local que o psicólogo trabalhe - pode ser na alta sociedade ou lá na periferia -, eu acho que ele tem que trabalhar isso, porque em todo lugar que o ser humano tiver ele tem que estar de modo igual, com os mesmos direitos e ele tem que estar com autonomia para se colocar, para se posicionar e brigar! E, de alguma forma, o trabalho do psicólogo tem que estar de acordo com o SUS, né? Ele tem seus preceitos!

O SUS, assim como a psicologia, tem recente formação, portanto, ambos ainda estão em processo de construção e revisão. Ainda que não funcione como o ideal, tem-se um SUS real, como atesta psicólogo/a 04: "Ao mesmo tempo em que o SUS no papel oferece a rede, mas ela como instituição não trabalha como ela propõe".

Psicólogo/a 06 reflete acerca dos princípios e diretrizes do SUS:

Ajudam nos meus atendimentos e no que eu quero quando eu vou planejar as atividades, mas ainda é muito ideal. Eu vejo eles como muito ideal e difícil de serem atingidos, mas é possível. Se o profissional se disponibilizar, é possível. Eu acho, assim, desde a graduação, eles (os princípios e diretrizes do SUS) devem ser trabalhados, para a gente ter o conhecimento. Acho que eles devem ser trabalhados. A questão da participação social que eu não tinha conhecimento, vim ter conhecimento na pós, e eu deveria conhecer isso na graduação. E eu acho que devia se cobrar mais desses profissionais.

Nota-se, a partir dessas reflexões, que o SUS é formado por uma diversidade de saberes entre estes, o saber psicológico. Assim sendo, faz parte de um sistema de saúde regido pela integralidade, universalidade e equidade. Logo, as ações em saúde empreendidas precisam ser voltadas para um modo de fazer saúde consciente de que se tem um modelo de SUS que ainda não se edifica na prática, porém, para que ele o seja, depende não só de uma série de atores sociais, mas também e diretamente dos profissionais de saúde que nele atuam cotidianamente, a partir de uma proposta de atenção à saúde de excelência.

\section{Considerações finais}

Entre as reflexões produzidas por esta pesquisa, entende-se que tão importante quanto conhecer e compartilhar modos de atuação psicológica no SUS é a necessidade de compreender que não é possível a construção de um modelo de atuação que seja eficaz em todo e qualquer nível de complexidade, cultura ou demanda anunciada pela população. Está-se diante de uma ciência que enseja uma singular atuação frente a cada contexto em que a psicologia seja chamada a estar.

Logo, em se tratando de pessoas e necessidades, nada é estático, já que profissionais de psicologia são impelidos a refletir que o tecnicismo e o automatismo, padronagens muitas vezes desejadas pela ciência e até por alguns profissionais, não devem ser alvo de desejo da psicologia enquanto ciência e profissão. 
Outrossim, reconhece-se e aposta-se na diversidade de possibilidades de práticas e na criatividade profissional frente à construção de espaços e formas de atuação que atendam às especificidades demandadas pela população e pelo próprio SUS.

Assim, considera-se que voltar o olhar para questões que permeiam a inserção da psicologia no SUS, sob a percepção de psicólogos que atuam no referido sistema, é relevante para fomentar reflexões críticas no âmbito do saber e do fazer psicológico, buscando construir subsídios para uma atuação ampliada e eficiente.

No presente estudo, foi possível vislumbrar a psicologia como uma ciência jovem, que está sendo refletida e discutida cotidianamente, embora ainda de forma individualizada. Percebe-se que a prática do profissional de psicologia vem se reafirmando ou se diferenciando nos contextos de APS e média complexidade, pois esse profissional volta seu olhar ao sujeito, tentando compreendê-lo de modo integral e contextualizado.

$\mathrm{O}$ abrangente leque de possibilidades de atuação do psicólogo no SUS é percebido quando os participantes desta pesquisa relatam práticas grupais, que vão de uma atuação com grupos específicos de usuários até trabalhos voltados aos profissionais, que, na maioria das vezes, atuam de modo multidisciplinar sendo o psicólogo parte dessa equipe -, sempre considerando as singularidades no instante em que se propõem as ações desenvolvidas.

Recorrentemente citada pelos profissionais psicólogos, a atuação multiprofissional traz consigo ganhos ao fazer do psicólogo, como possibilidade de propor ações que contemplem distintos modos de compreensão do sujeito, contribuindo para a efetivação da integralidade. Concomitantemente, atuar em equipe multidisciplinar evidencia a necessidade de o profissional psicólogo buscar uma gama de aportes teóricos, pois as linhas entre os fazeres/saberes que compõem essa equipe são tênues e precisam ser suficientemente claras para todos os profissionais que dela fazem parte.
São necessárias partilhas de experiências, de saberes, de práticas exitosas. São necessárias reflexões e ações coletivas frente aos desafios para que se possam elaborar estratégias de enfrentamento das dificuldades, tanto na psicologia - com seus profissionais aliados ao órgão de classe - quanto das demais profissões que reúnem saberes para oferecer assistência ao usuário do SUS. Compreende-se, ainda, que é necessário que a atuação do psicólogo em contextos ligados ao SUS alie conhecimento teórico e prático a uma genuína disponibilidade e interesse, para que se possa melhor contemplar o sujeito e atuar frente a ele de modo eficaz e eficiente.

Considera-se o SUS - seja na APS, seja na média complexidade - como um espaço de atuação que vem despertando interesse de atuação em profissionais psicólogos. Fica evidenciado, contudo, que os referidos profissionais sentem que a formação universitária não os prepara suficientemente para ocupar esses espaços, buscando aportes que fundamentem sua prática profissional, sobretudo no nível da pós-graduação. O diálogo entre pares, com a partilha (e o acúmulo) de experiências, não parece ter sido, todavia, um recurso usado. O presente estudo se propõe a ser mais um entre os meios de reflexão coletiva sobre o psicólogo em interface com o SUS.

Considera-se que a solidificação da psicologia no SUS funciona, enfim, como um indicativo de que fatores subjetivos, emocionais, sociais, culturais, históricos e políticos precisam ser pensados como determinantes de saúde, que, para além de patologias fisiológicas, existem outros fatores ligados à díade saúde-doença.

É assim que se problematiza a entrada da psicologia no SUS: como uma abertura de possibilidades de intervenções em saúde, pautadas nos fatores supracitados, através de uma conduta profissional integralizadora junto a equipes multiprofissionais, munindo-se de um olhar biopsicossocial ao sujeito usuário do sistema de saúde. Para tanto, vislumbra-se um constante movimento de ir e vir, de usar estratégias já conhecidas e de se aventurar no novo, construindo, reconstruindo e demarcando espaços e modos de atuação. 


\section{Colaboradoras}

Souza VA (0000-0001-7232-7561)* e Mendonça ES (0000-0003-0031-3608)* participaram ativamente da pesquisa e elaboração do manuscrito, contribuindo para concepção, delineamento e redação do trabalho, análise e discussão dos resultados e todas as revisões até a finalização do texto.

\section{Referências}

1. Ferreira Neto JL. Promoção da Saúde: práticas grupais na estratégia de saúde da família. São Paulo: Hucitec; 2011.

2. Paim JS. Sistema Único de Saúde (SUS) aos 30 anos. Ciênc. Saúde Colet. 2018; 23 (6):1723-1728.

3. Feio A, Oliveira CC. Confluências e divergências conceituais em educação em saúde. Saúde Soc. 2015; 24 (2):703-715.

4. Euzébios Filho A, Guzzo RSLG. Psicologia e Consciência de Classe "Para-Si”: ações e desafios na direção da mudança social. Rev. psicol. polít. 2015; 15(33):255-268.

5. Cintra MS, Bernardo MH. Atuação do Psicólogo na Atenção Básica do SUS e a Psicologia Social Psicologia. Psicol. cienc. prof. 2017; 37(4):883-896.

6. Paim J. Conferência: Determinantes Sociais de Saúde Jairnilson Paim. In: Ministério da Saúde. Anais I Seminário sobre a Política Nacional de Promoção da Saúde. Brasília, DF, 2009.

7. Spink MJ. Psicologia Social e Saúde: práticas, saberes e sentidos. 8. ed. Petrópolis: Vozes; 2011. 344 p.

8. Spink MJ. A ética na pesquisa social: da perspectiva prescritiva a interanimação dialógica. Psico. 2000; 31(1):17-22.
9. Minayo MCS. Pesquisa social: teoria, método e criatividade. 29. ed. Petrópolis: Vozes; 2013.

10. Ferreira VS. Artes e manhas da entrevista compreensiva. Saúde Soc. 2014; 23(3):979-992.

11. Bardin L. Análise de conteúdo. São Paulo: Edições 70; 2011.

12. Ferreira Neto JL. A Atuação do Psicólogo no SUS: análise de alguns impasses. Psicol., Ciênc. Prof. (Impr.). 2010; 30(2):390-403.

13. Alexandre ML, Romagnoli RC. Prática do Psicólogo na Atenção Básica - SUS: conexões com a clínica no território. Contextos Clínic. 2017; 10(2):284-299.

14. Quadros L. Desafios da prática clínica na formação de psicólogos: revendo fronteiras e criando possibilidades. Rev. IGT Rede. 2012; 9(17):187-199.

15. Cintra MS, Bernardo MH. Atuação do Psicólogo na Atenção Básica do SUS e a Psicologia Social. Psicol., Ciênc. Prof. (Impr.). 2017; 37(4):883-896.

16. Dettmann APS, Aragão EMA, Margotto LR. Uma perspectiva da Clínica Ampliada: as práticas da Psicologia na Assistência Social. Fractal, Rev. Psicol. 2016; 28(3):362-369. and Contributor ID). 
17. Sundfeld AC. Clínica ampliada na atenção básica e processos de subjetivação: relato de uma experiência. Physis. 2010; 20(4):1079-1097.

18. Ferreira-Neto JL. A Atuação do Psicólogo no SUS: Análise de Alguns Impasses. Psicol. ciênc. prof. 2010; 30(2):390-403.

19. Angerame VA. Psicologia hospitalar: teoria e prática. 2. ed. São Paulo: Cengage Learning; 2010. 120 p.

20. Matheus BR, Almeida MMS, Ferreira BO. Possibilidades de atuação profissional do psicólogo no âmbito da atenção básica em saúde. Rev. bras. promoç. saúde (Impr.). 2016; 29(1):117-123.

21. Azevedo NS, Kind L. Psicologia nos Núcleos de Apoio à Saúde da Família em Belo Horizonte. Psicol. ciênc. prof. 2013; 33(3):520-535.

22. Campos RHF. Psicologia Social Comunitária: na solidariedade a autonomia. Petrópolis: Vozes; 2010.

23. Medeiros MAT, Braga-Campos FC, Moreira MIB. A integralidade como eixo da formação em proposta interdisciplinar: estágios de Nutrição e Psicologia no campo da Saúde Coletiva. Rev. Nutr. 2014; 27(6):78598.

24. Anjos Filho NC, Souza AMP. A percepção sobre o trabalho em equipe multiprofissional dos trabalhadores de um Centro de Atenção Psicossocial em Salvador, Bahia, Brasil. Interface (Botucatu). 2017; 21(60):6376.

25. Camelo SHH. O trabalho em equipe na instituição hospitalar: uma revisão integrativa. Cogitare Enferm. 2011; 16(4):734-740.

26. Saldanha SV, Rosa AB, Cruz LR. Psicólogo Clínico e a equipe multidisciplinar no Hospital Santa Cruz. Rev. SBPH. 2013; 16(1):185-198.

27. Spink MJP. A Psicologia em diálogo com o SUS: prática profissional e produção acadêmica. São Paulo: Casa do Psicólogo; 2007.

Recebido em 27/03/2020

Aprovado em 28/08/2020

Conflito de interesses: inexistente

Suporte financeiro: não houve 